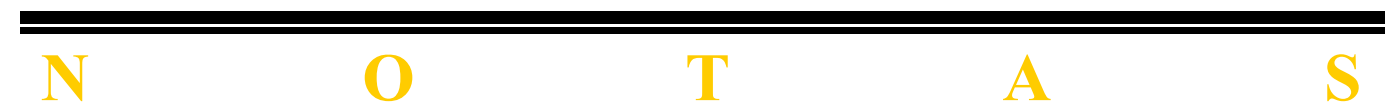




\title{
LOS PRESUPUESTOS ONTOLÓGICOS DEL DERECHO (A propósito de una crítica de Rafael Hernández Marín a la «concepción estándar del Derecho»)
}

\begin{abstract}
«Cuando persuadidos de estos principios recorremos las bibliotecas, ¡qué estragos deberíamos hacer! Tomemos en nuestra mano, por ejemplo, un volumen de teología o de metafísica escolástica y preguntémonos: ¿Contiene algún razonamiento abstracto acerca de la cantidad y el número? ¿No? ¿Contiene algún razonamiento acerca de los hechos y las cosas existentes? ¿Tampoco? Pues entonces arrojémoslo a la hoguera porque no puede contener otra cosa que sofismas y engaños»»

(Hume, Investigaciones sobre el entendimiento humano)

«La economía ontológica está muy bien cuando está libre de cargas -o al menos es barata. Pero quizás se compre a un precio demasiado alto si requiere que paguemos costes substanciales en términos de satisfacciones intelectuales de explicación y comprensión»».
\end{abstract}

(Nicholas Rescher, Scientific Realism)

\section{Introducción}

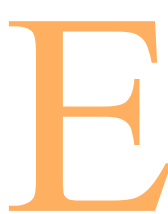

n octubre de 1994 el profesor Rafael Hernández Marín formó parte del tribunal que juzgó mi tesis doctoral Acción y norma en G. H. von Wright. En algún pasaje de mi tesis, yo afirmaba que la concepción «factualista» o «empirista» de las normas, que él sostiene, «puede tener consecuencias contraintuitivas para los estudiosos de la teoría de las normas y los juristas en general» ${ }^{1}$. La concepción factualista de las normas identifica a éstas con textos significativos (o enunciados con un significado literal). Esto hace posible afirmaciones como la siguiente: «las entidades jurídicas son objetos físicos, existentes en el espacio y en el tiempo, que pueden ser destruidos (quemados, por ejemplo) y dejar de existir» ${ }^{2}$. Sigo pensando que esta afirmación resulta, cuanto menos, «chocante», y que permite consideraciones no menos extrañas. Por ejemplo: ¿Para qué queremos estudiar la derogación (que tantos quebraderos de cabeza puede proporcionar) si basta con quemar una norma para que ésta deje de existir? Es más: la norma seguiría existiendo aunque

${ }^{1}$ Daniel González Lagier, Acción y norma en G. H. von Wright, Centro de Estudios Constitucionales, 1995, pág. 346.

${ }^{2}$ Rafael Hernández Marín, Teoría general del Derecho y de la Ciencia jurídica, Ed. PPU, 1989, pág. 50 . 
hubiera sido derogada por otra norma, pues ¿cómo puede un texto hacer desaparecer a otro texto? O estas otras (que, más que extrañas, la mayoría de los juristas y de los no juristas considerarían sin sentido): ¿Dónde está el Derecho? ¿Quién lo guarda? ¿Es muy grande? ¿De qué color es?

Consideraciones de este tenor fueron las que me llevaron a afirmar -afirmación que hoy todavía sostengo- que la concepción factualista podía tener consecuencias contraintuitivas. Sin embargo, ni en el texto de mi tesis ni en mis respuestas a Rafael Hernández Marín justifiqué adecuadamente mi postura. En aquél momento prometí al profesor Hernández Marín meditar con mayor detenimiento sobre su concepción de las normas. La publicación de su artículo «La concepción estándar y la concepción realista del Derecho ${ }^{3}$ me da la ocasión adecuada para cumplir mi promesa, tratando de rebatir los argumentos por los que el autor considera que la concepción factualista de las normas o -como la llama ahora- concepción realista pura del Derecho, es preferible a nuestra concepción cotidiana: la concepción estándar del Derecho.

El artículo de Rafael Hernández Marín comienza con una descripción de ambas concepciones. La tesis central de la concepción estándar -que es la concepción que subyace a la cultura jurídica continental europea- es la afirmación de que «los componentes esenciales del Derecho son la ley (concebida idealmente), el Derecho consuetudinario y los principios generales del Derecho» ${ }^{4}$. En opinión del autor, esta tesis suele ser completada en la mayoría de casos «con la idea de que del Derecho en general también forma parte un Derecho no positivo, un Derecho natural: sea en forma de principios o normas, sea como valores jurídicos, sea como derechos humanos, etc. ${ }^{5}$. La concepción realista pura, por su parte, se caracteriza por sostener: $" 1^{\circ}$ ) que no hay más Derecho que el Derecho positivo; $2^{\circ}$ ) que no hay más Derecho positivo que la ley; $3^{\circ}$ ) que no hay más ley que el texto de la ley; $4^{\circ}$ ) que ese texto legal es un hecho, un objeto físico» ${ }^{6}$. Tras describir ambas concepciones, Hernández Marín argumenta a favor de la concepción realista. Sus argumentos se dividen en argumentos en un plano teórico y argumentos en un plano práctico. Espero que el siguiente sea un resumen fiel de

\footnotetext{
${ }^{3}$ Rafael Hernández Marín, «La concepción estándar y la concepción realista del Derecho», Anuario de Filosofía del Derecho, núm. XII, 1995, págs. 347-361. 347.

${ }^{4}$ Rafael Hernández Marín, «La concepción estándar y la concepción realista del Derecho», pág. 347.

${ }^{5}$ Rafael Hernández Marín, «La concepción estándar y la concepción realista del Derecho», pág. 348.

${ }^{6}$ Rafael Hernández Marín, «La concepción estándar y la concepción realista del Derecho», pág.
} 
los mismos (los dos últimos argumentos son de índole práctica, mientras que el resto son teóricos):

(1) La concepción realista pura es la única que reúne las dos siguientes características: (1a) es respetuosa con los usos lingüísticos; (1b) es una concepción empírica (mientras que la concepción estándar es idealista).

(2) La concepción estándar es menos «sólida» que la concepción realista porque requiere más presupuestos ontológicos y porque sus tesis ontológicas son más que dudosas, incluso para las teorías ontológicas actuales más tolerantes.

(3) La concepción estándar incurre en un error metodológico, pues no distingue entre teorías que requieren para su desarrollo presupuestos ontológicos «amplios» (admisión del Derecho consuetudinario, de los principios generales del Derecho, de los valores, identificación entre normas y proposiciones o cuasiproposiciones, etc.) y aquellas que requieren exclusivamente presupuestos ontológicos justificados (existe el texto de la ley).

(4) Para solucionar el problema planteado por las leyes injustas o insuficientes, la concepción estándar propugna el recurso a entidades no existentes (el Derecho consuetudinario, los valores, los principios, etc.), tratando de derivar la existencia de tales entidades a partir de su necesidad práctica.

(5) Para regular la solución de los casos en los que las reglas legales son injustas o insuficientes, la doctrina y los legisladores -que suscriben mayoritariamente la concepción estándar- formulan reglas correctoras de la legalidad, que establecen cuándo recurrir a la analogía, cuándo declarar nulo un acto por fraude de ley, cuándo recurrir al Derecho consuetudinario o a los principios generales del Derecho, etc. Estas reglas plantean un grave problema de seguridad jurídica, pues padecen de vaguedad tanto en sus supuestos de hecho como en las consecuencias que prevén.

\section{La concepción realista, la concepción estándar y «los usos lingüísticos»}

Vayamos con el primero de los argumentos (o, más exactamente, la primera parte del primero de los argumentos). Hernández Marín sostiene que «los usos lingüísticos relativos a la palabra "Derecho" establecen dos cosas: a) que la Constitución, el Código civil, etc. , forman parte del Derecho; y b) qué es lo que dicen (literalmente) los artículos o apartados de la Constitución, del Código Civil, etc. » ${ }^{7}$. Esto deja fuera algunas teorías sobre el Derecho; por ejemplo, la teoría del Derecho de Th. Geiger, que califica de Derecho

\footnotetext{
347.

${ }^{7}$ Rafael Hernández Marín, «La concepción estándar y la concepción realista del Derecho», pág.
} 
«cosas que nadie califica como tales» (como regularidades de comportamiento) y excluye del Derecho cosas que «todo el mundo califica como tales» (como la Constitución, el Código Civil, etc. $)^{8}$.

Ahora bien, el alcance de estas afirmaciones en el artículo de Hernández Marín no me queda claro, por dos razones:

a) En primer lugar, parece haberse deslizado algún error cuando se afirma que «los usos lingüísticos relativos a la palabra "Derecho"» establecen no sólo que la Constitución, etc. es Derecho, sino también «qué es lo que dicen (literalmente) los artículos o apartados de la Constitución, del Código Civil, etc.»». Como es obvio, cuál es el significado de los artículos de la Constitución, el Código civil, etc. dependerá de los usos lingüísticos relativos a las palabras incluidas en tales textos, pero no de los usos lingüísticos relativos a la palabra «Derecho» (salvo en los casos en que esta palabra aparezca en tales textos).

b) En segundo lugar, surge la cuestión de qué usos lingüísticos hay que tener en cuenta: ¿los de los juristas (y qué juristas: jueces, abogados, dogmáticos, teóricos del Derecho,...)? ¿Los de los ciudadanos en general? Ésta no es una cuestión marginal: es posible que los usos de distintos grupos de hablantes no coincidan, y habrá que determinar a qué grupo darle preferencia. Hernández Marín parece dar preferencia a los usos lingüísticos de los no juristas. Pero esta es una decisión que habría que justificar. Volveré sobre esto.

En todo caso, Hernández Marín reconoce que «sí respetan dichos usos [lingüísticos] tanto la concepción estándar, como la concepción realista» ${ }^{10}$. Las divergencias entre ambas concepciones se producen en un ámbito que va más allá de los usos lingüísticos:

«Todas éstas [las cuestiones en las que difieren ambas teorías] son cuestiones sobre las que los usos lingüísticos de los no juristas, o sea, de aquellos que no sostienen una determinada concepción ontológica del Derecho, no se pronuncian: dichos usos lingüísticos no permiten determinar si la Constitución (el Código civil, etc.) se identifica o no con su texto, ni si hay otro derecho distinto al de los Cuerpos Jurídicos, ni tampoco si dicho texto es un hecho o una idea». ${ }^{11}$

De acuerdo con este párrafo, el argumento de los usos lingüísticos, por sí solo, no es un argumento contra la concepción estándar. Sin embargo, a

\footnotetext{
${ }^{8}$ Rafael Hernández Marín, «La concepción estándar y la concepción realista del Derecho», pág. 349.

${ }^{9}$ Rafael Hernández Marín, «La concepción estándar y la concepción realista del Derecho», pág. 349.

${ }^{10}$ Rafael Hernández Marín, «La concepción estándar y la concepción realista del Derecho», pág. 349.

${ }^{11}$ Rafael Hernández Marín, «La concepción estándar y la concepción realista del Derecho», pág. 349.
} 
mí me parece que se le puede «dar la vuelta» para usarlo precisamente contra la concepción realista.

Vayamos por partes. ¿Qué es lo que hace que el argumento de los usos lingüísticos -o el recurso al lenguaje ordinario como método filosófico- esté justificado? Hernández Marín señala que «respetar mínimamente los usos lingüísticos es condición necesaria para la comunicación humana $\rangle^{12}$. Pero debe haber algo más en el lenguaje ordinario, en los usos lingüísticos, porque si no bastaría con una estipulación que fuera aceptada por todos para sortear el argumento. El siguiente párrafo de John L. Austin apunta directamente a la importancia filosófica y metodológica del lenguaje ordinario:

«... nuestro común stock de palabras incorpora todas las distinciones que los hombres han hallado conveniente hacer, y las conexiones que han hallado conveniente establecer, durante la vida de muchas generaciones; seguramente es de esperar que éstas sean más numerosas, más razonables dado que han soportado la larga prueba de la supervivencia del más apto, y más sutiles, al menos en todos los asuntos ordinarios y razonablemente prácticos, que cualesquiera que plausiblemente usted o yo pudiéramos pensar en nuestros sillones una tarde -el método alternativo más socorrido-» ${ }^{13}$.

Si tiene razón Austin -y es difícil negar que tiene razón en parte-, el lenguaje recoge los matices, las distinciones, las conexiones, etc. que necesitamos para «movernos» en un determinado ámbito. Esta información implícita en el lenguaje ordinario nos puede ser útil para conocer el mundo. Seguramente incluye una cierta concepción ontológica. Ahora bien, probablemente sería un error fijamos en el lenguaje que usan los filósofos cuando tratan de explicar el mundo o poner un poco de orden en nuestra imagen de él. Ellos ya no utilizan un lenguaje ordinario, por lo que su lenguaje ya no tiene las virtudes de las que nos hablaba Austin. Tendrá otras virtudes, pero pocas veces ha soportado «la larga prueba de la supervivencia del más apto», no es una construcción colectiva más o menos espontánea, no está libre de la visión parcial de un autor o una concepción.

¿Ocurre algo semejante con el Derecho? Cuando nos referimos, ya no a la comprensión del mundo en general, sino del Derecho en particular, ¿debemos dejar de lado el lenguaje de los juristas? Esto es lo que parece indicar Hernández Marín: que debemos tener en cuenta los usos lingüísticos «de los no juristas, o sea, de aquellos que no sostienen una determinada concepción ontológica del Derecho». Sin embargo, dado el carácter especializado del Derecho, difícilmente existirán usos lingüísticos interesantes

\footnotetext{
${ }^{12}$ Rafael Hernández Marín, «La concepción estándar y la concepción realista del Derecho», pág. 350.

${ }^{13}$ John L. Austin, «Un alegato en pro de las excusas», Alianza Universidad, 1989, pág. 174.
} 
entre no juristas. El lenguaje del Derecho no es un lenguaje común, sino un lenguaje que ha desarrollado una comunidad que se dedica a una actividad específica. Los ciudadanos necesitan incorporar a su lenguaje cierta información sobre el Derecho, pero los juristas tienen que incorporar una información mucho mayor. El «lenguaje ordinario» del Derecho es fundamentalmente el lenguaje de los juristas (jueces, abogados, operadores jurídicos en general, y también dogmáticos, porque su función es eminentemente práctica o técnica). La desconfianza hacia el lenguaje de los filósofos debe traducirse exclusivamente en desconfianza (en cierto tipo de desconfianza) hacia el lenguaje de los filósofos del Derecho (especialmente los que sostienen explícitamente una concepción ontológica del Derecho, como Hernández Marín y yo mismo, en este momento), pero no hacia el resto de los juristas: éstos pueden sostener implícitamente una concepción ontológico-jurídica, pero no teorizan sobre ella; en realidad, ni siquiera se la plantean. Y si éste es el lenguaje en el que nos fijamos, nos daremos cuenta de que los usos lingüísticos de la mayoría de los juristas incorporan una concepción ontológica distinta de la que Hernández Marín llama realista pura (como él mismo reconoce en su artículo) ${ }^{14}$.

No voy a insistir más en este argumento. Al fin y al cabo, como el propio Austin dice, el lenguaje ordinario no es la última palabra, sino tan sólo la primera. Además, existe una objeción que puede hacerse al argumento de los usos lingüísticos o del lenguaje ordinario; es la siguiente: la información que el lenguaje ordinario incorpora, ¿es información (teórica) sobre cómo es el mundo o información (práctica) sobre cómo movemos en el mundo? Es posible que se trate de información útil para resolver problemas prácticos cotidianos, pero no nos diga cómo es realmente el mundo. $\mathrm{Y}$ esto es lo que nos preocupa: ¿Cómo es realmente el mundo del Derecho? ¿Cuáles son las entidades jurídicas últimas que existen de verdad? Estas cuestiones parecen presuponer dos cosas: (a) que podemos conocer la realidad objetiva; y (b) que existe una ancha brecha entre nuestro conocimiento teórico y nuestro conocimiento práctico. A propósito del siguiente argumento de Hernández Marín diré algo sobre todo esto.

${ }^{14}$ Podría argumentarse que, puesto que los juristas aceptan mayoritariamente una concepción estándar del Derecho, tratar de fundamentar esta concepción en sus usos lingüísticos resulta circular. Pero obsérvese que esta circularidad no existe porque los juristas no aceptan explícitamente esta concepción, y no han construido un lenguaje adecuado a esa concepción. Lo que mi argumento quiere decir es lo siguiente: (a) Los juristas tienen que cumplir con una función específica; (b) en el cumplimiento de esa función se ha ido creando cierto lenguaje; (C) dicho lenguaje ha incorporado una determinada concepción ontológica. El lenguaje de los juristas, como el lenguaje ordinario, tiene, en cierto sentido, «vida propia». 


\section{El argumento del carácter idealista de la concepción estándar}

«La segunda característica esencial -escribe Hernández Marín- de la concepción realista consiste en que ésta es una concepción empírica o factualista del Derecho». Por el contrario, la concepción estándar es -al menos parcialmente- una concepción idealista:

«En cuanto se admita un Derecho distinto del Derecho positivo (esto es, en cuanto se admita un Derecho natural); o bien un Derecho positivo distinto de la ley (como los principios generales del Derecho o el Derecho consuetudinario), o bien se rechace la identificación entre la ley y el texto de la ley (concibiendo las leyes como integradas por proposiciones o cuasiproposiciones), se está sosteniendo, al menos parcialmente, una concepción idealista, no empírica, del Derecho» ${ }^{15}$.

Lo primero que podría decirse a propósito de este argumento -que la concepción estándar no es una concepción empírica del Derecho- es que sólo es un buen argumento para quien piense que una concepción adecuada del Derecho debe ser una concepción empírica. Pero esto es precisamente lo que Hernández Marín trata de demostrar en su artículo, de manera que este argumento no añade nada nuevo y tampoco veo cómo puede afectar a la concepción estándar. Sin embargo, aun así, no me parece correcto afirmar que la concepción estándar es una concepción idealista, o parcialmente idealista. Si se la califica así, hay que explicitar por qué.

Para Hernández Marín «el Derecho está integrado por hechos y sólo por hechos» ${ }^{16}$. Esta afirmación le lleva a sostener las tres tesis siguientes:

«1 $\left.{ }^{\mathrm{a}}\right)$ La Constitución, el Código Civil, etc. , se identifican con su texto respectivo, o sea, con lo que literalmente dicen los artículos o apartados de la Constitución, del Código Civil, etc. Consecuencia de ello (y de la tesis que afirma que la Constitución, el Código Civil, etc. forman parte del Derecho) es que lo que forma parte del Derecho es el texto de la Constitución, el texto del Código Civil, etc.; en una palabra, que lo que forma parte del Derecho es el texto de la ley.

$2^{a}$ )No hay más Derecho que el texto de la ley.

$3^{a}$ )El texto de la ley es un hecho» ${ }^{17}$.

¿Qué significa en estos párrafos la palabra «hecho»? Parece que significa «objeto físico». El texto de la ley es un objeto físico («ese texto legal es un hecho, un objeto físico» $\left.{ }^{18}\right)$. Como tal, tiene una existencia «real». Supongo

\footnotetext{
${ }^{15}$ Rafael Hernández Marín, «La concepción estándar y la concepción realista del Derecho», pág. 351.

${ }^{16}$ Rafael Hernández Marín, «La concepción estándar y la concepción realista del Derecho», pág. 350.

${ }^{17}$ Rafael Hernández Marín, «La concepción estándar y la concepción realista del Derecho», pág. 349.

${ }^{18}$ Rafael Hernández Marín, «La concepción estándar y la concepción realista del Derecho», pág. 348.
} 
que esta existencia real se demuestra porque los objetos físicos se pueden «tocar»o «ver», o son susceptibles de algún experimento científico: su existencia es empíricamente demostrable. De manera que el argumento contra la concepción estándar dice así:

PRIMERA FORMULACIÓN: «La concepción estándar es idealista porque admite la existencia de entidades que no son objetos físicos».

¿Pero no es ésta una concepción ontológica demasiado restringida? Hernández Marín nos dice que los presupuestos ontológicos de la concepción estándar son tan dudosos que ni las concepciones ontológicas actuales más tolerantes los admitirían; por mi parte voy a tratar de mostrar que los presupuestos ontológicos de la concepción realista («sólo existen los objetos físicos») son tan -ingenuamente- estrictos que hasta las concepciones ontológicas actuales más severas los rebasan.

Me parece que el problema básico de la concepción de Hernández Marín es haber adoptado un concepto homogéneo de «existencia», que toma como paradigma de existencia el modo de existencia de los objetos físicos. En las líneas que siguen voy a tratar de exponer cómo creo que hay que entender el concepto y los modos de «existencia».

\section{1. La distinción entre hecho y objeto físico}

Un buen punto de partida puede ser advertir la falta en el artículo de Hernández Marín de una distinción que me parece relevante: la distinción entre hecho y objeto físico. Una noción ampliamente extendida de «hecho» hace depender de ellos la verdad o falsedad de nuestras creencias. Russell, por ejemplo, define precisamente a los hechos como aquello que hace verdaderas o falsas a nuestras creencias (en realidad, Russell habla indistintamente de proposiciones y creencias; Rafael Hernández Marín no cree en la existencia de proposiciones, esto es, cree que las proposiciones no existen, pero si cree que las proposiciones no existen, no puede negar que hay creencias). En palabras de Bertrand Russell:

«Cuando hablo de un "hecho" -no me propongo alcanzar una definición exacta, sino una explicación que les permita saber de qué estoy hablando- me refiero a aquello que hace verdadera o falsa a una proposición. Si digo "Está lloviendo", lo que digo será verdadero en unas determinadas condiciones atmosféricas y falso en otras. Las condiciones atmosféricas que hacen que mi enunciado sea verdadero (o falso, según el caso), constituyen lo que yo llamaría un "hecho". Si digo "Sócrates está muerto", mi enunciado será verdadero debido a un cierto suceso fisiológico que hace siglos tuvo lugar en Atenas» ${ }^{19}$.

\footnotetext{
${ }^{19}$ Bertrand Russell, «La filosofía del atomismo lógico», en J. Muguerza (selección), La concepción analítica de la filosofía, Alianza Universidad, pág. 144.
} 
Pero si los hechos se definen de esta manera -como aquello que hace verdaderas o falsas a nuestras creencias-, entonces los objetos físicos no son hechos, porque ellos no hacen verdaderas o falsas a nuestras creencias:

«Es preciso tener en cuenta -continúa Russell- que cuando hablo de un hecho no me refiero a una cosa particular existente, como Sócrates, la lluvia o el sol. Sócrates no hace por sí mismo verdadero ni falso a ningún enunciado (...) Cuando una palabra aislada alcanza a expresar un hecho, como "fuego" o "el lobo", se debe siempre a un contexto inexpresado, y la expresión completa de tal hecho habrá de envolver siempre una oración $\rangle^{20}$.

De manera que, de acuerdo con una definición ampliamente asumida de «hecho» (como es sabido, en este punto Russell no es original) el texto de la ley no es un hecho, es un objeto físico. Su existencia sí es un hecho, así como la posesión de ciertas propiedades. Pero entonces, ¿existen los hechos o sólo existen los objetos físicos? Russell dice lo siguiente:

«Lo primero en que he de hacer hincapié es en que el mundo exterior -el mundo, por así decirlo, que nuestro conocimiento aspira a conocer- no queda exhaustivamente descrito por medio de una serie de «particulares» [entre los que se encuentran los objetos físicos], sino debemos asimismo tener en cuenta lo que yo llamo hechos, los cuales corresponden al género de cosas expresadas mediante una oración y forman parte del mudo real en la misma medida que las sillas y las mesas particulares ${ }^{21}$.

Para comprender el mundo no nos basta con objetos particulares, sino que también necesitamos hablar de hechos: tenemos que hablar de cambios en el mundo físico, de acciones humanas, de la posesión de ciertas características por parte de los particulares, etc. Pero es obvio que los hechos no existen en el mismo sentido en que existen los particulares: que mi perro esté a la derecha de mi gato es un hecho, es algo con lo que hay que contar para describir el mundo, pero es obvio que el hecho de que mi perro esté a la derecha de mi gato tiene una existencia de un tipo peculiar (quizá debiéramos decir que los objetos particulares existen, pero los hechos suceden o tienen lugar o son el caso). De la misma manera, los sucesos físicos, las acciones, etc., «existen» (porque debemos contar con ellos para describir el mundo) en un sentido peculiar (distinto del sentido en que existen los objetos que cambian o los agentes que actúan).

Podemos extraer de todo esto tres conclusiones: (a) una concepción factualista o empírica del Derecho no tiene por qué ser necesariamente una concepción sobre el Derecho como un objeto físico, a diferencia de lo que parece pensar Rafael Hernández Marín (como veremos, esto es importante para poder determinar las condiciones de existencia de las reglas consuetudinarias,

\footnotetext{
${ }^{20}$ Bertrand Russell, «La filosofía del atomismo lógico», pág. 144.

${ }^{21}$ Bertrand Russell, «La filosofía del atomismo lógico», pág. 145.
} 
y quizá también de los principios); (b) al distinguir entre objetos (o particulares) y hechos, debemos distinguir entre dos modos (o sentidos) de existencia (o de lo que hay en el mundo); (e) la decisión de introducir hechos junto con objetos físicos en la descripción de lo que hay es una decisión guiada por la necesidad de explicar mejor el mundo ${ }^{22}$.

\section{2. La fiabilidad de la ciencia}

Aunque hayamos distinguido entre objetos y hechos, podría decirse que una concepción empírica será aquella que se ocupa de objetos o hechos que pueden ser contrastados empíricamente; esto es, aunque haya dos modos de existencia -uno para los objetos y otro para los hechos-, puede postularse que ambos deben ser «sentidos empíricos de existencia» (los hechos también pueden ser susceptibles de comprobación empírica). En la medida en que la concepción estándar del Derecho haga referencia a entidades que no tienen una existencia empírica, entonces será una concepción idealista. Ahora el argumento del idealismo de la concepción estándar diría así:

SEGUNDA formulación: «La concepción estándar es idealista porque admite hechos o particulares cuya existencia no puede ser comprobada empíricamente». Para enfrentamos a la nueva forma de esta objeción debemos tener presente la distinción entre lo que realmente existe y lo que creemos que realmente existe.

Filósofos de la ciencia de orientaciones bien diversas -Popper, Feyerabend, Kuhn, Lakatos, Quine, etc.- aceptan que la ciencia (cuya misión es conocer el mundo, para explicar, predecir o controlar los sucesos que ocurren en él) no es una empresa infalible. Todo conocimiento científico es -al igual que los acusados antes de ser declarados culpables«presunto» conocimiento, y sigue siendo «presunto» aunque sea considerado verdadero. Continuando con las metáforas jurídicas, podemos decir que la ciencia no tiene toda la verdad, ni tampoco nada más que la verdad.

La inestabilidad de la ciencia presenta varias facetas:

a) En primer lugar, las teorías científicas nunca pueden dejar de ser meras estimaciones incompletas -aunque sean las mejores que podemos hacer- que avanzamos desde la perspectiva de un conjunto de conceptos y conocimientos disponible en un momento determinado. Cuando cambia este conjunto de conceptos (bien porque son revisados y modificados, bien porque son totalmente sustituidos tras lo que Kuhn llama una «revolución científica»),

\footnotetext{
${ }^{22}$ Y para hacerlo probablemente no nos baste con particulares y hechos, sino que tengamos que incluir también propiedades y, quizá, relaciones. Pero este es un tema donde no tendremos que entrar.
} 
aparecen «nuevas realidades» ante nosotros, y puede que desaparezcan algunas de las «viejas realidades». «Es algo así -dice Kuhn- como si la comunidad profesional fuera transportada repentinamente a otro planeta, donde los objetos familiares se ven bajo una luz diferente $\mathrm{y}$, además, se les unen otros objetos desconocidos $»^{23}$. Y esta relatividad no es sólo un rasgo exclusivo de la ciencia, sino también de nuestra comprensión cotidiana del mundo y de nuestras discusiones filosóficas; y no sólo es relatividad respecto a nuestros conceptos, sino respecto a aspectos más básicos, como estructuras lingüísticas. Resultan sumamente curiosos -entre muchos otros- los estudios de Benjamín Whorf basados en el vocabulario y la gramática a propósito de una de las controversias ontológicas más venerables de nuestra cultura: la distinción entre forma y materia. La explicación de Whorf' de esta controversia es como sigue: Los europeos suelen emplear una «fórmula de recipiente» para referirse a aquellos «sustantivos de masa que designan continuos ilimitados» (agua, leche, madera, tela, etc.). Así, decimos «beber un vaso de agua», «coger un palo de madera» o «un pedazo de tela». Es esta característica del pensamiento la que ha predispuesto a los europeos para establecer la distinción entre «forma»y «materia» y a organizar su conocimiento en términos de «sustancias» que permanecen inmutables a través del tiempo. En cambio, entre los hopi los sustantivos mencionados no tienen el mismo matiz (no sugieren algo ilimitado), pueden decir «bebo un agua», por lo que -en opinión de Whorf- su mundo se ha construido como «un mundo de sucesos», y no un mundo de cosas o de sustancias ${ }^{24}$.

b) En segundo lugar, como señala Nicholas Rescher, todas nuestras creencias aceptadas pueden resultar falsas, porque no podemos saltar el vacío entre lo que parece que es verdadero y lo que realmente es verdadero por medios lógicamente seguros: «es perfectamente posible -y no sólo teóricamente, sino realmente posible- que uno pudiera jugar correctamente el juego de la investigación científica con arreglo a todas las reglas aceptadas y, sin embargo, llegar a un resultado que no es verdadero» ${ }^{25}$.

c) En tercer lugar, muchas de nuestras creencias aceptadas resultarán ser falsas. La historia nos ha enseñado que no hay razón para considerar nuestra ciencia actual como un sistema perfecto de conocimientos: "aprendemos mediante investigación empírica sobre la investigación empírica, y una de las principales cosas que aprendemos es que en ningún estadio real

${ }^{23}$ Thomas S. Kuhn, La estructura de las revoluciones científicas, Fondo de Cultura Económica, 1994, pág. 176.

${ }^{24}$ Tomo la descripción de las investigaciones de Whorf de W. T. Jones, Las ciencias y las humanidades, Fondo de Cultura Económica, 1976, pág. 157 y ss.

${ }^{25}$ Nicholas Rescher, Los límites de la ciencia, Ed. Tecnos, 1994, pág. 112. 
ofrece la ciencia un resultado definitivo e inmutable $\rangle^{26}$. Esto es lo que Rescher llama «copernicanismo cognitivo»: así como la revolución copernicana original implicó darnos cuenta de que nuestra posición en el espacio no supone ningún privilegio ontológico, ahora nos damos cuenta de que nuestra posición en el tiempo no supone ningún privilegio cognitivo ${ }^{27}$.

La consecuencia de todo ello la expresa Kuhn en el siguiente párrafo:

«No hay, creo, una forma de teoría independiente para reconstruir frases como "realmente ahí"; la noción de un paralelo entre la ontología de una teoría y su contraparte "real" en la naturaleza, ahora me parece un principio ilusorio; además, como historiador, estoy impresionado con la falta de plausibilidad de esta perspectiva. No dudo, por ejemplo, que la mecánica de Newton mejora a la aristotélica y que la de Einstein perfecciona la de Newton como instrumento para resolver enigmas. Pero no puedo ver en su sucesión ninguna dirección coherente de desarrollo ontológico». ${ }^{28}$

Estas consideraciones podrían llevamos a un escepticismo en materia científica; sin embargo, esta conclusión resulta descartable gracias al hecho de que, aunque no contamos nada más que con un «presunto» conocimiento, hoy es evidente que éste ha permitido un importante avance en el nivel tecnológico. Algunos autores, como Rescher, señalan que el progreso científico se manifiesta con mayor claridad en el hecho de que la ciencia aumenta cada vez más nuestra capacidad de resolución de problemas y control del mundo ${ }^{29}$. Volveremos sobre esto. Otra conclusión -que es la que deseo destacar ahora- es la necesidad de tener siempre presente la distinción entre lo que realmente existe y lo que creemos que existe, entre realidad y conocimiento, entre el mundo y nuestra imagen del mismo.

Una vez que distinguimos ambas esferas, parece razonable pensar que para que una concepción sobre cualquier cosa sea considerada una concepción empírica no es necesario exigir que trate sobre entidades que realmente existen (porque entonces nunca podríamos saber si una teoría es o no empírica), sino que debe bastamos con aseguramos de que trata sobre entidades que creemos que existen, o -si queremos ser coherentes con una visión científica del mundo-, que la ciencia cree que existen. Si modificamos consecuentemente el argumento contra la concepción estándar, éste diría lo siguiente:

TERCERA FORMULACIÓN: «La concepción estándar es idealista porque admite hechos o particulares de un tipo que los científicos creen que no existe».

\footnotetext{
${ }^{26}$ Nicholas Rescher, Los límites de la ciencia, pág. 113.

${ }^{27}$ Nicholas Rescher, Los límites de la ciencia, pág. 116.

${ }^{28}$ Thomas S. Kuhn, La estructura de las revoluciones cientificas, Posdata de 1969, pág. 314.

${ }^{29}$ Nicholas Rescher, Los límites de la ciencia, pág. 121.
} 
Para enfrentamos a esta nueva versión del argumento debemos preguntamos por los criterios que usamos (que los científicos usan) para llegar a las creencias sobre lo que existe.

\section{3. La dimensión pragmática de nuestras creencias sobre lo que existe}

Hemos visto que la realidad «que está ahí fuera» no se nos impone de una manera definitiva sino que, más bien al contrario, se escurre entre las mallas de nuestras redes teóricas y cambia según la red que usemos. Con esto no quiero decir que la realidad no se nos imponga en alguna medida. La postura que pretendo sostener no niega la existencia de hechos y objetos reales, sino que trata de reconciliar dos ideas, una sugerida por el sentido común y otra sugerida por la filosofía y la historia de la ciencia: por un lado, que existe una realidad objetiva; por otro lado, que nuestra percepción de esa realidad está influida en un grado importante por determinados condicionamientos conceptuales y estructuras mentales ${ }^{30}$.

Lo que creemos sobre el mundo es una imagen que hemos construido nosotros mismos de algo realmente existente. Y somos conscientes de ello. Lo asombroso de todo este asunto es que al mismo tiempo que actuamos como si nuestro conocimiento fuera realmente verdadero, no tenemos seguridad de que lo sea. Tenemos que conciliar ambas cosas. ¿Por qué seguimos investigando? ¿Por qué asumimos nuestras verdades como si describieran realmente lo que existe, a pesar de todas nuestras dudas? ¿Por qué no abandonamos la empresa científica y volvemos al mito y la superstición?

La respuesta (o una de las respuestas), como he adelantado antes, es que la ciencia, a pesar de sus imperfecciones, es un instrumento sumamente útil; el conocimiento científico permite un desarrollo tecnológico que cada vez nos abre más posibilidades de transformación del mundo. La curiosidad no es el único estímulo para la investigación científica, porque sabemos que esa curiosidad nunca podrá ser realmente satisfecha. El mayor estímulo es probablemente la recompensa que podemos obtener en el nivel tecnológico, porque en este nivel sí parece haber progreso:

«En el fondo, el progreso de la ciencia se manifiesta de la manera más clara en los aspectos prácticos, más bien que en los teóricos. El progreso de la ciencia depende crucialmente de sus aplicaciones; estriba en la dimensión pragmática de esta empresa -en el éxito creciente de sus aplicaciones a la resolución y

${ }^{30}$ Esta postura es la que Rescher llama «interaccionismo». Véase Anna Estany, Introducción a la filosofía de la ciencia, Ed. Crítica, 1993, pág. 46. En este libro puede encontrarse un resumen de las distintas actitudes ontológicas (realismo, relativismo, etc.). En el artículo de Quine, «Acerca de lo que hay» (en Willard Van O. Quine, Desde un punto de vista lógico, ed. Orbis, 1984), encontramos también un resumen de las distintas actitudes y criterios relacionados con la «decisión ontológica». 
control de problemas, en que provea un dominio de la naturaleza no sólo cognitivo, sino también físico» ${ }^{31}$.

Si nos damos cuenta de la importancia que la dimensión pragmática tiene en nuestro conocimiento teórico como recompensa y estímulo, no nos debe costar reconocer lo que constituye la otra cara de la misma moneda: el hecho de que entre los criterios que usamos para dar por existente una entidad, ocupen un lugar importante factores pragmáticos. No sólo escogemos una u otra concepción del mundo guiados por ellos, sino que los científicos han acabado incluso aceptando la existencia de entidades que no podemos comprobar empíricamente, pero que aumentan nuestra capacidad de explicar, predecir o controlar acontecimientos. Esto es ya un fenómeno generalizado, y en la mayoría de las ciencias -incluso en física- contamos, junto con los «conceptos observacionales», con los llamados «conceptos teóricos», que no pueden ser comprobados empíricamente pero nos resultan útiles o incluso necesarios. Conceptos como el de gravedad, electrón, campo magnético, gen, virus, etc. son conceptos teóricos ${ }^{32}$.

Por supuesto, la admisión de conceptos teóricos no implica que cualquier concepto que imaginemos pueda ser introducido en una ciencia; debe haber alguna justificación para introducirlo. Sólo si nos resultan de utilidad para explicar, predecir o controlar el mundo está justificado que se introduzcan. El concepto de gravedad, por ejemplo, es «una fabricación de nuestra mente para que logremos nosotros una explicación del universo, mejor que otras posibles, que nos capacita para hacer previsiones de acontecimientos futuros, como la fecha exacta de los eclipses o la precisión de la órbita de un satélite artificial al que enviamos para explorar otros planetas de nuestro sistema solar» ${ }^{33}$.

¿Hasta qué punto son sólo ficciones los conceptos teóricos? Si tales conceptos teóricos cumplen la función de ayudamos a comprender y controlar el mundo, podemos llegar a pensar incluso que no son meras ficciones, que algo de realidad hemos atrapado con ellos, que es posible que hagan referencia a algo existente «ahí fuera». Esto es lo que parece sugerir el siguiente párrafo de Einstein e Infeld a propósito del concepto de «campo magnético»:

«El concepto de campo fue, en un principio, sólo un medio para facilitar la explicación de los fenómenos eléctricos desde un punto de vista mecánico (...)

\footnotetext{
${ }^{31}$ Nicholas Rescher, Los limites de la ciencia, pág. 121.

${ }^{32}$ Sobre la distinción entre ambos tipos de conceptos, puede verse, por ejemplo, Anna Estany, Introducción a la filosofía de la ciencia, págs. 100 y ss. Sobre esta distinción en el ámbito de las ciencias sociales, puede verse Richard S. Rudner, Filosofía de la ciencia social, Alianza Universidad, 1980, págs. 44 y ss.

${ }^{33}$ Manuel Trevijano Etcheverría, En torno a la ciencia, Ed. Tecnos, 1994, pág. 121-122.
} 
Lentamente, y a través de una verdadera lucha, el concepto de campo alcanzó un lugar de privilegio en la física y ha continuado siendo uno de los conceptos básicos de la misma. El campo electromagnético es para el físico moderno tan real como la silla sobre la cual se sienta» ${ }^{34}$.

Quizá podría recapitularse lo dicho hasta aquí recordando que debemos tener presente la distinción entre (1) el mundo de lo que realmente existe ahí fuera y (2) la imagen del mundo que hemos construido. Esta imagen incluye (2.1) aquellas cosas que creemos que existen porque en la medida de lo posible hemos comprobado que existen (de acuerdo con, y con las limitaciones de, nuestro paradigma conceptual actual) y (2.2) aquellas cosas que creemos que existen porque, aunque no podamos comprobarlos empíricamente, si no postuláramos su existencia, no podríamos explicar, predecir o controlar un sector importante del mundo.

Respecto a nuestra imagen del mundo, a nuestras creencias acerca de lo que realmente existe, hemos visto (a) que elegimos una teoría científica y la concepción ontológica que presupone en lugar de otra teoría y otra concepción ontológica en función de su potencial explicativo y práctico, y (b) que postulamos la existencia de ciertas entidades (hechos o particulares) porque de esta manera aumentamos también el potencial explicativo y práctico de una teoría ${ }^{35}$.

Trasladando todo esto a nuestro problema inicial -la objeción de idealismo contra la concepción estándar del Derecho-, tendríamos que reformular el argumento como sigue:

\footnotetext{
${ }^{34}$ Albert Einstein y Leopold Infeld, La evolución de la física, Salvat, 1993, pág. 122.

${ }^{35}$ Cuando me refiero a la dimensión pragmática de nuestra imagen (científica) del mundo no estoy tratando de sugerir un criterio de demarcación de la ciencia. En las páginas anteriores no he pretendido afirmar que es ciencia todo aquello que permite explicar, predecir o controlar mejor el mundo, o un aspecto del mismo, sino exclusivamente destacar que el criterio para determinar qué entidades se admiten en una teoría científica es en última instancia un criterio práctico: se admiten aquellas entidades que resultan más útiles para explicar, predecir o controlar el conjunto de fenómenos que constituyen el objeto de estudio de tal ciencia. Este criterio guarda cierta relación con el concepto de verdad de William James. En opinión de Juan Antonio Pérez Lledó podemos distinguir dos criterios en la teoría de la verdad de James: un criterio pragmático «débil» y un criterio pragmático «fuerte». De acuerdo con el criterio «débil» una creencia es verdadera cuando tiene utilidad cognoscitiva (esto es, cuando nos permite ordenar, clasificar, asimilar o integrar nuevos datos en nuestro conocimiento); de acuerdo con el criterio «fuerte», una creencia es verdadera cuando tiene utilidad práctica en la vida (Juan Antonio Pérez Lledó, El instrumentalismo jurídico en Estados Unidos, inédito). Si trasladamos esta distinción a nuestro criterio de existencia, creo que, para evitar una excesiva multiplicación de entidades, deberíamos exigir ambos criterios conjuntamente: esto es, la postulación por parte de los científicos de la existencia de una entidad debe ser coherente con el resto del conocimiento del que disponemos y, además, debe tener utilidad para los fines de la ciencia (por ejemplo, debe permitir explicar mejor algún suceso). Sin embargo, el primero de los requisitos (la coherencia con el resto de nuestro conocimiento) ha de ser tomado con ciertas precauciones, pues en caso contrario puede convertirse en un criterio excesivamente conservador.
} 
CUARTA FORMULACIÓN: «La concepción estándar del Derecho es idealista porque acepta hechos y particulares cuya existencia no es necesaria para explicar, predecir o controlar ningún fenómeno relevante relacionado con el Derecho».

Ahora el argumento tiene una forma totalmente nueva, y ya no resulta tan evidente el carácter idealista de la concepción estándar. Como en cierto sentido la discusión ha dejado de ser teórica para ser práctica (ahora se trata de determinar qué teoría, si la realista o la estándar, es más útil para explicar, predecir o controlar algún fenómeno relevante relacionado con el Derecho, y no cuál presupone una ontología «más ajustada a la realidad»), retrasaré la defensa frente a este argumento hasta llegar a los argumentos prácticos de Rafael Hernández Marín.

\section{El argumento de la «solidez»}

\section{1. La pretendida «debilidad» de la concepción estándar}

El tercer argumento de Rafael Hernández Marín contra la concepción estándar del Derecho plantea la debilidad de esta última frente a la mayor solidez de la concepción realista pura. Esta mayor debilidad se debe a dos razones: En primer lugar, la concepción estándar presupone la existencia de muchas más cosas que la concepción realista (la concepción realista sostiene solamente que existe el texto de la ley, mientras que la concepción estándar sostiene también la existencia del Derecho consuetudinario, de proposiciones o cuasiproposiciones legales, de principios generales del Derecho, etc.). Esto constituye un defecto, porque «es obvio que cuanto más cosas presuponga una doctrina, tanto más débil resulta, dado que el riesgo de equivocarse es mayor. Dicho en dos palabras: cuanto más habla uno, más fácil es equivocarse» ${ }^{36}$. En segundo lugar, la concepción estándar es también más débil porque sus tesis ontológicas «son en sí mismas más que dudosas; dudosas incluso para filósofos que admitan la existencia de entidades ideales. De hecho, ni siquiera las doctrinas ontológicas actuales más tolerantes las aceptarían» ${ }^{37}$.

Estos argumentos pierden fuerza si se tiene en cuenta el papel de los factores pragmáticos en la construcción de nuestra imagen del mundo y la aceptación de entidades teóricas en las ciencias ${ }^{38}$. Además, como veremos

\footnotetext{
${ }^{36}$ Rafael Hernández Marín, «La concepción...», pág. 351.

${ }^{37}$ Rafael Hernández Marín, «La concepción...», pág. 351.

${ }^{38}$ No obstante, es cierto que existen teorías actuales cuyo compromiso ontológico es ciertamente asombroso (y demasiado arriesgado). Una manera de rebatir el segundo argumento -según el cual las teorías ontológicas actuales más tolerantes no admitirían la concepción estándar- consiste en proporcionar ejemplos de estas teorías. Ahí va uno: Se ha formulado una
} 
más adelante, ni los principios generales del Derecho ni mucho menos las reglas consuetudinarias son en realidad entidades puramente teóricas. No obstante, voy a recordar un ejemplo histórico -sin duda conocido- ante el que podemos plantearnos cómo hubiera sido la historia de nuestra ciencia si no se hubiera arriesgado una hipótesis altamente improbable en su tiempo.

\section{2. Las dudas de Galileo}

Hacia el final de 1609 Galileo comenzó a dedicarse apasionadamente a la observación de los cuerpos celestes ${ }^{39}$. El 7 de Enero de 1610 dirigió casualmente su telescopio hacia Júpiter y vio tres pequeñas estrellas, demasiado pequeñas para ser percibidas a simple vista. Podemos representar la posición de estas estrellas respecto al planeta con el siguiente esquema («o» representa a Júpiter):

$$
* * 0 *
$$

Estas estrellas no habían sido observadas con anterioridad, pero esto no tenía nada de extraño, pues dondequiera que se apuntara un telescopio tan potente como el suyo se observaban estrellas que ningún hombre había visto. Aunque no había nada extraordinario en ellas -«llevado por alguna extraña fatalidad», nos dice-, Galileo volvió a mirar hacia Júpiter la noche siguiente. Lo que vio entonces fue esto:

$$
\text { o *** }
$$

¡Pero eso sí que era extraordinario! Más que extraordinario, jera imposible! Todo el mundo sabía y había sabido desde hacía siglos que los únicos objetos móviles que había en el cielo eran los siete planetas. Todas las demás estrellas estaban inmóviles, incrustadas en una esfera cristalina que giraba en

teoría que trata de explicar los sucesos mentales llamada funcionalismo homuncular. Para el funcionalismo homuncular: «las funciones cognitivas son realizadas por un hombrecillo (homunculus) que tenemos dentro de la cabeza». Pero la cosa no queda ahí. Postular que nuestras funciones mentales las realiza un hombrecillo que vive dentro de nuestra cabeza plantea un serio problema de regreso al infinito, pues ¿quién realiza las funciones del homúnculo que vive dentro de nuestra cabeza? ¿Un hombrecillo más pequeño? Para resolver esta objeción, el funcionalismo homuncular «apoya la postulación de homúnculos dentro de una persona, pero evita la objeción del regreso postulando un gran número de ellos, cada uno de los cuales es más estúpido que el sistema global pero realiza una tarea necesaria para todo el sistema». El último de ellos, el más estúpido (y más pequeño) de todos, realiza una tarea puramente mecánica, que puede explicarse sin postular otro hombrecillo. Aunque una primera reacción ante esta teoría podría ser la de considerarla una broma, serios filósofos de la mente mencionan esta teoría y le prestan atención (Becthtel, Dennet, Lycan, etc.). Comparada con el funcionalismo homuncular, yo diría que la concepción estándar del Derecho no resulta en absoluto disparatada. Véase William Becthtel, Filosofía de la mente. Una panorámica para la ciencia cognitiva, Ed. Tecnos, 1991, pág. 162.

${ }^{39}$ Galileo dejó escritas sus observaciones y razonamientos en un libro publicado en 1610: El mensajero sideral. Tomo la narración de este hecho de W. T. Jones, Las ciencias y las humanidades, págs. $20 \mathrm{y}$ ss. 
un movimiento cotidiano y formaba una especie de telón de fondo, muy lejos, detrás de los planetas móviles. Puesto que sólo había siete planetas, las estrellas que se descubrieran debían ser estrellas fijas (y no podía haber más de siete planetas, porque se creía que su número había sido establecido por la voluntad divina como un recuerdo constante de las siete virtudes que deberíamos cultivar y los siete vicios que deberíamos repudiar). De manera que era imposible que las estrellas se movieran, pero se habían movido.

Galileo invitó a un colega de la Universidad de Padua a observar las tres nuevas estrellas, pero éste se negó a aceptar la invitación aduciendo que o bien Galileo estaba equivocado y no había estrellas móviles o bien era peligroso mirarlas. Galileo no se desanimó. La noche del 9 estuvo nublado, pero la noche del 10 vio las estrellas de esta forma:

$$
* * 0
$$

Las estrellas habían vuelto a moverse, y una de ellas había desaparecido. Galileo trató de encontrar una solución al enigma. Había muchas probabilidades de que la observación fuera falsa, de que estuviera equivocado. Se trataba de comparar una observación con una creencia firmemente arraigada a escala mundial y desde hacía mucho tiempo. No obstante, a pesar de lo altamente improbable que parecía su teoría, arriesgó la siguiente explicación: Las tres estrellas no se encontraban sujetas a la esfera de las estrellas fijas, sino que debían estar girando alrededor de Júpiter, podían ser en realidad tres satélites; de esta forma se explicaría su movimiento y la desaparición de una de ellas (era invisible desde la Tierra porque estaba pasando detrás de Júpiter).

La solución de Galileo implicaba un nuevo esquema conceptual que impulsaría un profundo cambio no sólo de la astronomía, sino de la perspectiva del mundo en general. Tras la revolución que ejemplifica esta anécdota, el mundo no volvió a ser el mismo (por ejemplo, la imagen del mundo como el resultado de la voluntad divina comenzó a ser sustituida por una imagen científica del mismo: Dios se replegó a los cielos, o incluso más allá de ellos). Pero lo que debemos destacar de esta anécdota es que Galileo acertó porque arriesgó una hipótesis altamente improbable (tan improbable entonces como lo es ahora para nosotros el atravesar paredes sólidas o mover objetos físicos con el poder de la mente $\left.{ }^{40}\right)$. Podría haber callado -como su colega de la Universidad-, y no haber corrido el riesgo de equivocarse. Pero entonces no podría haber acertado (en el sentido de «acertar» que implica desarrollar una teoría que permite explicar, predecir o controlar mejor el mundo).

${ }^{40}$ Claro que esta observación no debe tomarse como un incentivo para creer las cosas más inverosímiles... mientras no tengamos certeza (epistemológica) de que son verdaderas. 
La contrapartida del argumento que se basa en el hecho de que cuanto más se dice más riesgo hay de equivocarse es que cuanto menos se dice menos probabilidad tenemos de acertar. Ni el nacimiento de la filosofía ni el de la ciencia, ni su historia, hubiera sido posible si el miedo a la equivocación hubiera impedido a los primeros filósofos aventurar sus -improbables- opiniones.

\section{El argumento del error metodológico. ¿Qué es «el texto de la ley»?}

Para Hernández Marín la concepción estándar incurre en el error metodológico de no permitir distinguir entre aquellas teorías jurídicas que requieren un compromiso ontológico restringido (sólo existe el texto de la ley) y aquellas que requieren de un compromiso amplio (también existen principios generales del Derecho, normas consuetudinarias, valores, etc.). Pero esta objeción resulta debilitada si nos damos cuenta de que «el texto de la ley» al que hace referencia Hernández Marín no es una entidad menos problemática que, por ejemplo, las normas consuetudinarias. ¿Qué es el «texto de la ley»? Hay varias interpretaciones posibles de la expresión, y Hernández Marín no aclara a qué se está refiriendo, aunque se supone que es la única entidad jurídica que realmente existe. Puesto que el texto de la ley es un objeto físico, debemos pensar que se trata de unas marcas concretas (letras) sobre un papel (mientras no se use un soporte informático) a las que atribuimos un significado. Pero resulta que hay muchos objetos físicos candidatos a ser «el texto de la ley»: el texto aprobado por los parlamentarios (pero es de suponer que cada uno tendrá una copia), el texto que se remite al rey para su promulgación, el texto que se remite al B. O. E. para su publicación, la primera copia que sale de la imprenta del B. O. E. (¿habrá que esperar veinte días para que el texto forme parte del Derecho?), la segunda copia, la tercera,... las publicaciones de las editoriales jurídicas, los apuntes de los estudiantes que copian literalmente los artículos que se reproducen en estas publicaciones, etc. ¿Es alguno de éstos el «texto de la ley»? ¿Lo son todos? ¿Si lo son todos, qué pasa si no coinciden -por ejemplo, por erratas-?

El hecho de que Hernández Marín se refiera genéricamente al «texto de la ley», sin especificar a cuál de estos textos, puede hacer pensar que esta expresión hace referencia más bien (como ocurre con su uso común) a una abstracción a partir de estos textos realmente existentes. Pero, en este caso, el «texto de la ley» no es un objeto físico.

Éstas son algunas de las preguntas que habría que aclarar antes de afirmar que la entidad «el texto de la ley» es menos problemática que el resto de entidades asumidas por la concepción estándar y reclamar la distinción entre teorías que requieren de uno o de otro compromiso ontológico. 


\section{El argumento de que la necesidad práctica no implica la existencia. ¿Son las reglas consuetudinarias, los principios, etc. conceptos puramente teóricos?}

«El partidario de la concepción estándar -escribe Hernández Marín- comete un error... al argumentar que existen reglas jurídicas no legales, dado que éstas son necesarias $\rangle^{41}$. Este argumento también es fácilmente sorteable una vez que somos conscientes de la distinción entre (1) lo que realmente existe y (2) lo que creemos que existe. Es cierto que la necesidad práctica y (1) son independientes. Pero, dado que nuestras creencias acerca de lo que existe están influidas por nuestras necesidades prácticas, surge una relación de dependencia entre (2) y éstas. Esta dependencia, que se da también en las ciencias de la naturaleza, se muestra con mayor evidencia en las ciencias humanas, simplemente porque el problema del conocimiento objetivo aparece en ellas con mayor énfasis.

No obstante, quisiera hacer dos matizaciones:

i) En primer lugar, resulta exagerado decir que creemos que existe todo aquello que necesitamos que exista. Una descripción más adecuada de esta relación es la que hemos visto más arriba: (1) entre dos teorías, escogemos aquella que permite explicar, predecir o controlar mejor nuestro objeto de estudio; (2) cuando un concepto teórico que hemos introducido con fines explicativos (o predictivos o de control) cumple satisfactoriamente su función, acabamos otorgando «status de entidad existente» a su referencia (creemos que realmente existe una fuerza de gravedad, y no sólo que los objetos actúan como si existiera).

ii) En segundo lugar, cuando se trata de sostener la existencia de normas consuetudinarias o principios no es necesario equiparar estos conceptos a conceptos puramente teóricos. Algunos filósofos de la ciencia sostienen que todos los conceptos observables están también cargados de teoría y que todos los conceptos teóricos presentan alguna manifestación empíricamente contrastable. La distinción entre ambos tipos de conceptos podría verse como un continuo entre dos extremos, en los que rara vez se sitúa un concepto. Seguramente, las reglas consuetudinarias y los principios se pueden explicar a partir de hechos (no sólo objetos físicos) observables. Hart, por ejemplo, señala las siguientes condiciones de existencia de las reglas sociales (cito una reconstrucción de Juan Carlos Bayón):

«Sintéticamente, para Hart se puede afirmar que existe en el grupo G una regla social a tenor de la cual "todo $\mathrm{S}$ debe hacer $\oslash$ en las circunstancias C" si y sólo si:

\footnotetext{
${ }^{41}$ Rafael Hernández Marín, «La concepción estándar...», pág. 355.
} 
1) Existe de hecho una cierta regularidad de comportamiento, es decir, dentro de $\mathrm{G}$ la mayor parte de los $\mathrm{S}$ hacen $ø$ en la mayor parte de las ocasiones en las que concurren las circunstancias $\mathrm{C}$;

2) las desviaciones respecto al comportamiento regular son motivo de crítica (...)

3) las conductas consistentes en manifestar esas reacciones críticas no suscitan a su vez reacciones críticas ulteriores por parte de los miembros de G (...)

4) los miembros de G -o al menos algunos de ellos- adoptan una "actitud crítica reflexiva" que se manifiesta en el uso del lenguaje normativo (esto es, de términos deónticos como "deber") y en apelaciones a la regla en cuestión para justificar a) por qué ellos mismos -si pertenecen a la clase de sujetos S- hacen ø cuando concurren las circunstancias $\mathrm{C}$; b) por qué critican a los $\mathrm{S}$ cuando se desvían de esa pauta de conducta-, y c) por qué no consideran a su vez objeto de crítica la manifestación de esas reacciones críticas» ${ }^{42}$.

Si se admite la existencia de hechos -y no sólo de objetos físicos-, en estas condiciones no parece haber nada cuya admisión exija un elevado grado de «idealismo». Por lo que respecta a los llamados principios generales del Derecho, hay que distinguir entre principios explícitos y principios implícitos ${ }^{43}$. Los primeros son aquellos que se encuentran mencionados explícitamente en «el texto de la ley» (como el reconocimiento en el artículo 14 de nuestra Constitución del derecho a la igualdad ante la ley); éstos pueden ser vagos y de difícil precisión, pero en la medida en que se encuentran en el «texto de la ley» su existencia no puede plantear problemas distintos a los de cualquier otra regla a una concepción como la de Hernández Marín. Los principios implícitos no se encuentran explicitados en el texto de la ley (no existen como formulación lingüística), pero sus condiciones de existencia y su contenido se pueden determinar sin recurrir a postular la existencia de entidades que carezcan por completo de conexión con la realidad. No puedo desarrollar aquí una formulación precisa que establezca los criterios de existencia de los principios implícitos, pero algunos ingredientes no sistematizados de la misma podrían ser los siguientes:

a) Una manera de concebir la relación entre los principios y las reglas consiste en partir de una concepción «de arriba a abajo» o «deductiva», como cuando los principios se ven como pautas de una moral objetiva a las cuales tienen que ajustarse el resto de normas. Plantearse si esta concepción nos obligaría a postular entidades puramente ideales nos lleva a la cuestión que Nino ha llamado la relación entre la praxis humana y la constitución de la moral. El proyecto kantiano de derivar la moral a partir de ciertos presupuestos

${ }^{42}$ Juan Carlos Bayón, La normatividad del Derecho: Deber jurídico y razones para la acción, Centro de Estudios Constitucionales, 1991, pág. 449.

${ }^{43}$ Sobre esta distinción véase Manuel Atienza y Juan Ruiz Manero, Las piezas del Derecho, Ed. Ariel, 1996, pág. 6 y ss. 
del razonamiento práctico individual; el de Allan Gewirth de derivarlos de los presupuestos de las acciones intencionales; o el de Apel, Habermas y el propio Nino de derivarlos de los presupuestos de la práctica social de la discusión moral ${ }^{44}$, son intentos de construir los principios morales como entidades con «anclaje» en una realidad que experimentamos más directamente. Pero afortunadamente no necesitamos entrar en estas cuestiones para fundar los principios generales del Derecho en tales realidades más próximas, porque podemos adoptar una concepción «inductiva» o «de abajo a arriba», para la cual los principios generales del Derecho son abstracciones y generalizaciones a partir de normas que sí se encuentran explicitadas en el texto de la ley; desde esta perspectiva, los principios jurídicos constituyen algo así como la «ideología» de un ordenamiento jurídico y se encuentran en una relación de interdependencia respecto al resto de normas del ordenamiento (en el sentido de que, por un lado, cuando cambian algunas de las reglas y principios explícitos del ordenamiento, pueden cambiar los principios implícitos $\mathrm{y}$, por otro lado, sirven de criterio de interpretación a estas normas y principios explícitos $)^{45}$.

b) Otra posibilidad (que no tiene por qué excluir a la anterior) consiste en considerar a los principios jurídicos (o a algunos de ellos) como procedentes, no de una moral objetiva, sino de la moral social o positiva de una comunidad, en cuyo caso estos principios son susceptibles de un análisis en términos de creencias compartidas y actitudes críticas semejante al de regla social.

c) De acuerdo con algunas distinciones sobre los principios (Dworkin; Manuel Atienza y Juan Ruiz Manero, etc.) cabe distinguir entre directrices y principios en sentido estricto $^{46}$. Las primeras son aquellas que determinan qué objetivos o finalidades debe perseguir el ordenamiento jurídico. Tratar de derivar los objetivos y finalidades implícitos en las instituciones jurídicas o en determinados sectores del ordenamiento jurídico a partir de su funcionamiento y de sus reglas, directrices y principios explícitos no puede plantear problemas cualitativamente distintos de los que pueda plantear tratar de derivar los propósitos individuales, proyectos de futuro y planes de vida de un sujeto a partir de su conducta y de sus creencias, opiniones e intereses conocidos.

${ }^{44}$ Carlos S. Nino, Derecho, moral y politica, Ed. Ariel, 1994, pág. 164 y ss.

${ }^{45}$ Ésta es la postura de Manuel Atienza y Juan Ruiz Manero en Las piezas del Derecho, pág. 24, donde afirman que "“X es un principio implícito" de una determinada institución, sector normativo o sistema jurídico es lo mismo que afirmar que las reglas y principios explícitos correspondientes son coherentes con $\mathrm{X}$ y que a tales reglas y principios explícitos, entendidos como formulaciones lingüísticas, debe adscribírseles un contenido proposicional que resulta coherente con $\mathrm{X}$ ».

${ }^{46}$ Manuel Atienza y Juan Ruiz Manero, Las piezas del Derecho, pág. 5. 
7. El argumento práctico: los problemas de las «reglas correctoras de la legalidad». Sobre la necesidad práctica del Derecho consuetudinario y los principios generales del Derecho

Es aquí donde se produce el enfrentamiento decisivo entre la concepción realista y la concepción estándar. Será preferible aquella concepción que permita explicar, predecir o controlar mejor algún aspecto relevante del Derecho o su práctica. Ahora bien, como la concepción estándar es familiar para la mayoría de juristas (por ello es estándar), en lugar de repetir sus virtudes y defectos voy a limitarme a presentar las razones por las que la alternativa realista no es una buena alternativa:

(1) Para Hernández Marín, uno de los problemas prácticos donde se muestra que la concepción realista pura es preferible a la concepción estándar es el problema de las reglas legales que se consideran injustas, insatisfactorias o inadecuadas. Señala Hernández Marín que este problema puede ser reconocido por los realistas porque «admitir la existencia de leyes injustas no implica asumir la existencia de una entidad ideal, "el valor justicia" ${ }^{47}$. De acuerdo con este argumento, es posible afirmar coherentemente "yo creo que esta ley es injusta» $\mathrm{y}$ «no creo en el valor de justicia». Pero, ¿son realmente compatibles ambas afirmaciones?

a) Supongamos que alguien dice "Yo creo que esta casa es grande», y a continuación «no creo en la propiedad "tamaño"». En este caso, o bien concluimos que «grande» significa para él algo distinto que para nosotros (y no relacionado con el tamaño) o bien que alguna de sus dos afirmaciones no son ciertas, porque no es posible predicar de un objeto una propiedad y luego negar la existencia de esa propiedad. De la misma manera, un escéptico no puede afirmar que una ley es injusta (o justa) y negar creer en esa propiedad. Por supuesto, puede negar que exista la propiedad como una entidad separada del objeto del que la predica, pero esto sólo significa que las propiedades tienen un tipo de existencia distinto al de los objetos, no que no existan (en el sentido de necesidad para describir el mundo).

b) Es posible que al decir «no creo en el valor justicia» el escéptico no quiera decir en realidad que no cree en la justicia, sino que no cree en la objetividad de la justicia. Por el contrario, algo es injusto porque él le atribuye tal propiedad (bien porque siente que es injusto, bien porque su atribución lo constituye como tal). Por tanto, cuando afirma «esta ley es injusta» está diciendo «esta ley es injusta porque para mí es injusta». Pero sostener una definición de justicia según la cual «justo (o injusto) es aquello que para

\footnotetext{
${ }^{47}$ Rafael Hernández Marín, «La concepción...», pág. 354.
} 
mí es justo (o injusto)» plantea enormes problemas ${ }^{48}$ : el más grave es que sitúa a los juicios morales fuera de la discusión racional, por lo que no puede fundamentar a partir de ellos ninguna conclusión que afecte a quien no comparta sus juicios. Si esto es lo que se quiere decir al afirmar «no creo en el valor justicia», es cierto -como afirma Hernán dez Marín- que el realista puede plantearse el problema de la justicia de las leyes, pero simplemente para decir que una ley es injusta (o justa) porque para él es injusta (o justa). Una vez llegados a esta afirmación casi tautológica, no puede seguir discutiendo. No hay que dar mayor consideración a su afirmación que si nos dijera que prefiere la mermelada de naranja amarga o los huevos poco hechos. Pero ésta es una actitud contraria a intuiciones lingüísticas ampliamente compartidas. En palabras de Norbert Hoester: «quien pronuncia un juicio moral formula, tácitamente, la pretensión de que su juicio está en condiciones de resistir una prueba racional, es decir, que, en última instancia, todos aquellos que son sobrios en sus opiniones, imparciales y desprejuiciados y están bien informados -cosa que él mismo pretende ser-, si se ponen a considerar la cuestión, coincidirán con su juicio» ${ }^{49}$.

(2) Señala Hernández Marín que para regular la solución de los casos en los que las reglas legales presentan deficiencias, la doctrina y los legisladores -que suscriben mayoritariamente la concepción estándar- formulan reglas correctoras de la legalidad (RCL), que establecen cuándo recurrir a la analogía, cuándo declarar nulo un acto por fraude de ley, cuándo recurrir al Derecho consuetudinario o a los principios generales del Derecho, etc. Las RCL, en su opinión, plantean un grave problema de seguridad jurídica, pues padecen de vaguedad en sus supuestos de hecho («fraude de ley», "caso no regulado por una regla legal, pero semejante a otro sí regulado», etc. $)^{50}$. Ahora bien, una concepción realista también debería ofrecer soluciones a los casos que prevén las RCL, y la vaguedad de estos supuestos de hecho no es algo que la concepción realista pueda solucionar. Por lo tanto la vaguedad del supuesto de hecho de las RCL no es un argumento contra la concepción estándar.

(3) El problema de inseguridad se agrava porque las RCL también padecen de vaguedad respecto a las consecuencias que prevén: «el conjunto de los principios (generales) del Derecho, el de las normas del Derecho natural

\footnotetext{
${ }^{48}$ Algunos de ellos serían los siguientes: (1) la definición incurre en un error lógico, al incluir el término que se quiere definir en la frase que lo pretende definir; (2) se excluye la posibilidad de genuina discusión acerca de la justicia, pues las discrepancias se reducen a diferencias de actitud; (3) una misma ley puede ser simultáneamente justa e injusta, pues diferentes personas pueden tener diferentes actitudes hacia la misma ley; etc.

${ }^{49}$ Norbert Hoester, Problemas de Ética Normativa, Ed. Fontamara, 1992, pág. 154.

${ }^{50}$ Rafael Hernández Marín, «La concepción...», pág. 356.
} 
o el conjunto de los valores jurídicos son conjuntos más que borrosos, nadie sabe con certeza todo lo que incluyen o todo lo que excluyen $\rangle^{51}$. Son posibles varias objeciones a este argumento:

i) Si es cierto que no existen estas entidades, como sostiene la concepción realista, entonces no puede haber «conjuntos borrosos» de principios, valores, etc. , sino simplemente conjuntos vacíos, con lo cual no cabe ninguna vaguedad. La crítica a la vaguedad de estos conjuntos sólo es una crítica que pueda realizarse si se abandona la concepción realista, es decir, es una crítica interna a la concepción estándar.

ii) Supongamos que alguien nos dice: «Los unicornios no existen, y aun admitiendo que existieran, tendrían mal carácter». ¿Es esto una objeción a la existencia de los unicornios? No lo es. De la misma manera, el argumento según el cual «los principios, etc. no existen, y si existieran, serían vagos» tampoco es un argumento contra la existencia de los principios, etc. ¿Puede ser un argumento para negar la conveniencia de que creamos en ellos? Sólo lo sería si (a) creer en los principios, etc. fuera totalmente inútil o (b) existiera una alternativa mejor. Respecto a (a), está claro que del hecho de que los principios, etc. sean vagos se puede concluir que en algunos casos serán inútiles, pero no que en todos los casos lo sean. (b) nos lleva a analizar la alternativa propuesta por Hernández Marín.

(4) Frente a las RCL, Hernández Marín propone una regla realista correctora de la legalidad (RRCL), que permitiría «la formulación de decisiones prudenciales (esto es, decisiones que no tienen otra base que la conciencia, prudencia, sentimientos, etc., de los jueces) sólo a las instancias superiores de la magistratura, siempre que no perjudiquen a un particular, y en aquellos casos en que la inconveniencia de la decisión legalista (basada en el texto literal de la ley), dictada por el órgano inferior, sea grande y patente» ${ }^{52}$. Sin embargo, esta regla no sirve para solucionar el problema de seguridad que plantean las RCL, porque tiene tres focos de inseguridad: (a) son los jueces los que estiman la inconveniencia de la decisión legalista, y deben hacerlo exclusivamente de acuerdo con su propio criterio (sin contar con la guía de los principios generales, los valores, etc.); (b) son los jueces los que estiman, de acuerdo exclusivamente con su propio criterio, si hay o no perjuicio a un $\operatorname{particular}^{53}$; (c) los jueces deben decidir de acuerdo con su propia conciencia, sentimientos, prudencia, etc.

\footnotetext{
${ }^{51}$ Rafael Hernández Marín, «La concepción...», pág. 357.

${ }^{52}$ Rafael Hernández Marín, «La concepción...», pág. 359.

${ }^{53}$ Obsérvese que el requisito de que la RRCL no perjudique a un particular excluye su aplicación en pleitos civiles, ya que en éstos siempre habrá perjuicio a uno de los particulares pleiteantes.
} 
Una vez advertido esto, nos encontramos ante la siguiente alternativa:

(a) O bien los principios generales del Derecho, las reglas consuetudinarias, etc. no existen, en cuyo caso los jueces, a pesar de las RCL, resuelven de hecho los casos de leyes inadecuadas recurriendo a su propia conciencia, sentimientos, prudencia, etc., por lo que la RRCL es superflua desde el punto de vista práctico.

(b) O bien existen tales entidades, en cuyo caso optar por la RRCL es la peor elección porque deja la decisión al arbitrio del juez en lugar de remitir a criterios que, aun siendo vagos, no son totalmente subjetivos y permiten la discusión y el control intersubjetivo.

Este último punto es el que marca realmente la diferencia entre la concepción estándar y la concepción realista. De acuerdo con nuestra explicación de estos tipos de normas, aunque el Derecho consuetudinario y los principios generales del Derecho formen parte de un conjunto borroso, y aunque su mismo contenido sea vago, la exigencia de que los jueces recurran a ellos en caso de insuficiencia de la ley para justificar sus decisiones permite algún control de éstas decisiones, cosa que no permite la concepción realista. Puede que, debido a esta vaguedad, la utilidad de los principios, etc. sea muy pequeña, pero ante la posibilidad de afectar a intereses de terceros, y ante la falta de alternativa mejor, cualquier pequeña utilidad tiene una importancia enorme, y no debemos despreciarla,

\section{Conclusiones}

Existen varias vías para defender la concepción estándar. Por ejemplo, puede mostrarse que en el ámbito de las ciencias sociales (pero no sólo en él) suele recurrirse a la construcción de modelos cuya aceptación depende de su capacidad descriptiva y explicativa de un sector de la realidad (en nuestro caso, social). Pero esta manera de argumentar no hace referencia a la noción de «existencia», por lo que un partidario de la concepción realista pura siempre podría aducir que tales modelos presuponen entidades que la ciencia no admite. Por ello he preferido dar un rodeo y mostrar los límites de nuestro conocimiento científico y los criterios que lo guían. En definitiva, mi defensa de la concepción estándar ha consistido en lo siguiente:

(1) He tratado de mostrar que los usos lingüísticos relevantes para esta cuestión son los de los juristas, y éstos avalan la concepción estándar.

(2) He tratado de mostrar que la noción de existencia no es homogénea y que, además de objetos físicos, admitimos la existencia de hechos, propiedades, etc. Esto abre la posibilidad de explicar los principios y las normas consuetudinarias como hechos.

(3) He señalado la necesidad de distinguir entre el mundo real y nuestra imagen del mundo real, y he tratado de mostrar que esta imagen está fuertemente 
ligada a criterios pragmáticos. Esto lleva la discusión sobre la existencia de los principios, etc. del terreno teórico al práctico.

(4) He argumentado que el Derecho consuetudinario y los principios generales del Derecho no son entidades puramente teóricas, sino que pueden explicarse a partir de conceptos observacionales.

(5) He mostrado que la concepción realista se enfrenta a serias dificultades cuando se plantea problemas de injusticia de las normas y que no logra presentar una alternativa que permita superar los problemas de inseguridad de los que acusa a la concepción estándar.

(6) He sostenido que, frente a la concepción realista, la concepción estándar permite explicar qué hacen los jueces cuando sostienen que basan una decisión en principios, etc.; permite predecir, vagamente, pero en alguna medida, cuál va a ser la decisión de los jueces; y sobre todo permite controlar la corrección jurídica de estas decisiones, esto es, determinar si está justificada esta decisión ${ }^{54}$.

En cierto lugar de su artículo, Rafael Hernández Marín sostiene: «el abandonar dicho marco [la ontología realista] (asumiendo alguno de los supuestos que configuran el marco ontológico-jurídico de la concepción estándar), para resolver un problema concreto, me crearía un problema teórico mayor que el que intento solucionar» ${ }^{55}$. Quizá se pueda resumir este ya demasiado extenso artículo diciendo que el principal problema teórico de la concepción realista pura es que tiene un grave problema práctico: es insuficiente para explicar el Derecho ${ }^{56}$.

\footnotetext{
${ }^{54}$ Para una descripción más amplia de las funciones que cumplen los principios jurídicos puede verse Manuel Atienza y Juan Ruiz Manero, Las piezas del Derecho, págs. 19 a 25. Estos autores distinguen tres dimensiones de los derechos: (a) una dimensión explicativa, no sólo de la conducta de los jueces, sino del funcionamiento del Derecho en general y de otras instituciones en particular, gracias a su poder sistematizador que les permite presentar de una manera breve y ordenada el ordenamiento jurídico; (2) una función justificativa en el razonamiento jurídico; y (3) una función legitimadora y de control del poder.

${ }^{55}$ Rafael Hernández Marín, «La concepción...», pág. 351.

${ }^{56}$ Hernández Marín es consciente de que éste puede ser un argumento contra la concepción realista, pero sostiene que es necesario partir primero de ella y sólo en el caso de que esta insuficiencia se muestre aumentar el compromiso ontológico. Por mi parte, creo que la historia del pensamiento jurídico ya ha recorrido ese camino, al menos desde la Escuela de la Exégesis.
} 
DOXA 21-I (1998) 